\title{
CALIPSO RECORDINGS AND MONITORING DUST STORMS OVER THE OPEN SEAS IN SOUTH OF THE IRAN PLATEAU Hamid R. Khalesifard ${ }^{1 *}$, Farizeh Bayat $^{1}$ \\ ${ }^{I}$ Department of Physics and Center for Research in Climate Change and Global warming, Institute for Advanced Studies in Basic Sciences, No. 444 Prof. Sobouti Blvd., Zanjan 4513766731, Iran, *khalesi@iasbs.ac.ir
}

\begin{abstract}
Open seas in the south of the Iran plateau are under the influence of heavy dust storms which are originating either from the Tigris and Euphrates basin, the Arabian Peninsula or Hamoun lake. We have used the recordings of the CALIPSO satellite to investigate the seasonal variations as well as the origins of the dust storms over the region. CALIPSO data set shows dust activities are frequent during May to September in the interested region and the Hamoun lake has considerable impacts on it.
\end{abstract}

\section{INTRODUCTION}

Iran, a country on the dust belt, is surrounded by several sources such as: Tigris and Euphrates basin in west, the region between the Caspian and Aral seas in north, and the Arabian Peninsula in south [1-3]. The well-known northwesterly Shamal wind, transfer dust plumes from the Mesopotamian region toward the Iran plateau and the Persian Gulf area $[1,2,4]$. Such dust activities may be intensified by other dust sources (like those inside the Arabian Peninsula) and influence on a quite wide region which extends up to the Arabian sea, Indian Ocean and Indian subcontinent [5]. Dust sources in the Arabian Peninsula mostly are located in the south and east sides of the Peninsula, where they are quit active during April to September [1, 4]. These sources mostly affect the Oman and Arabian seas, and even the Indian subcontinent but don't have considerable impacts on the Iran plateau $[2,4-6]$.

On the other hand, advected dust from the Hamoun lake in East Iran also affects the atmosphere over the Oman and the Arab seas and sometimes even the Indian Ocean. Such dust plums may also influence southwest Asian regions like Southeast
Iran and West Pakistan [2, 7-9]. East and southeast of Iran are under the influence of northerly wind known as Levar or "Sistan 120-day wind". Levar mostly is blowing during mid-May to midSeptember and can also lead to some changes in the climate of the Oman sea $[4,10,11]$.

This work is an effort on monitoring dust storms over the Persian Gulf and the Oman sea by using CALIPSO recordings during 2006 to 2015. For this purpose, columnar averaged particulate depolarization ratio (PDR), column integrated attenuated backscatter (IAB) and columnar aerosol optical depth (AOD) have been extracted from the CALIPSO level 2 data products. In the next part of this manuscript, after introducing the data set and calculations in section 2, results and discussions are presented in section 3 and finally the work is concluded in section 4 .

\section{DATA SET AND CALCULATIONS}

Four colored rectangles in Figure 1 depict the investigation regions. The regions are chosen in a way to cover almost all of the atmosphere over the open waters in south of the Iran plateau but prevent the land. The figure also depicts the 16-day, ground tracks of CALIPSO over the whole area. To investigate dust activities in the specified regions, $\mathrm{AOD}, \mathrm{PDR}$ and $\mathrm{IAB}$ at $532 \mathrm{~nm}$, have been extracted from the CALIPSO level $2 / 5 \mathrm{~km}$ aerosol profile V3, during June 2006 to December 2015. To assign a single value to each of the mentioned parameters, their averaged value over each ground track which is just inscribed inside one of the rectangles has been calculated. In order to finding the AOD, PDR and IAB single value for each ground tracks, all features which are not aerosols screened. Note that all these parameters have been obtained by considering data uncertainty and their valid range. After computing these attributed 
parameters to each ground tracks, their corresponding monthly and annual averaged values for each rectangle have been calculated.

One of the most essential factors for monitoring aerosols transport is wind speed and direction evaluations. In order to achieve this purpose, we have used daily vector wind NCEP/NCAR reanalysis with $2.5^{\circ} \times 2.5^{\circ}$ spatial resolution.

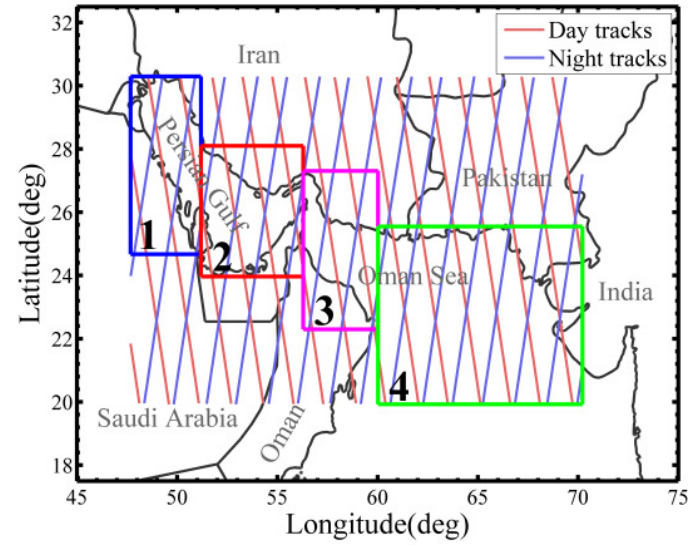

Figure 1. 16-day CALIPSO ground tracks, regions 1 to 4 are covering the investigation area.

\section{RESULTS AND DISCUSSIONS}

Figure 2 shows monthly variations of IAB, averaged over the whole data set. Comparing Figure $2 \mathrm{~d}$ with Figures 2a-2c, one can find, region 4 shows different behavior especially during June to September. PDR more or less shows the same behavior for all regions (not shown here) but again monthly values of AOD in region 4 are different respect to other regions (not shown here).

These differences will be more clear when one looks to variations of AOD versus IAB (Figure 3 ). Figures $3 \mathrm{a}-3 \mathrm{c}$ show the variations of 4-month averaged values of AOD versus IAB for February to May (FMAM), June to September (JJAS), and October to January (ONDJ). In Figure 3 all obtained AOD and IAB values for each 4-month, in any region, have been averaged and just a rectangle has been assigned to them. The rectangle is centered on the averaged value of AOD and IAB and its dimensions in the $\mathrm{x}$ and $\mathrm{y}$ directions are two times of the standard deviations of IAB and AOD data points. Figure $3 \mathrm{~b}$ very clearly shows that in JJAS, both the AOD and IAB have considerable increases in region 4. This is in temporal coincidence with the 120-day Sistan, Levar wind and the dry annual period for the Hamoun lake [12].
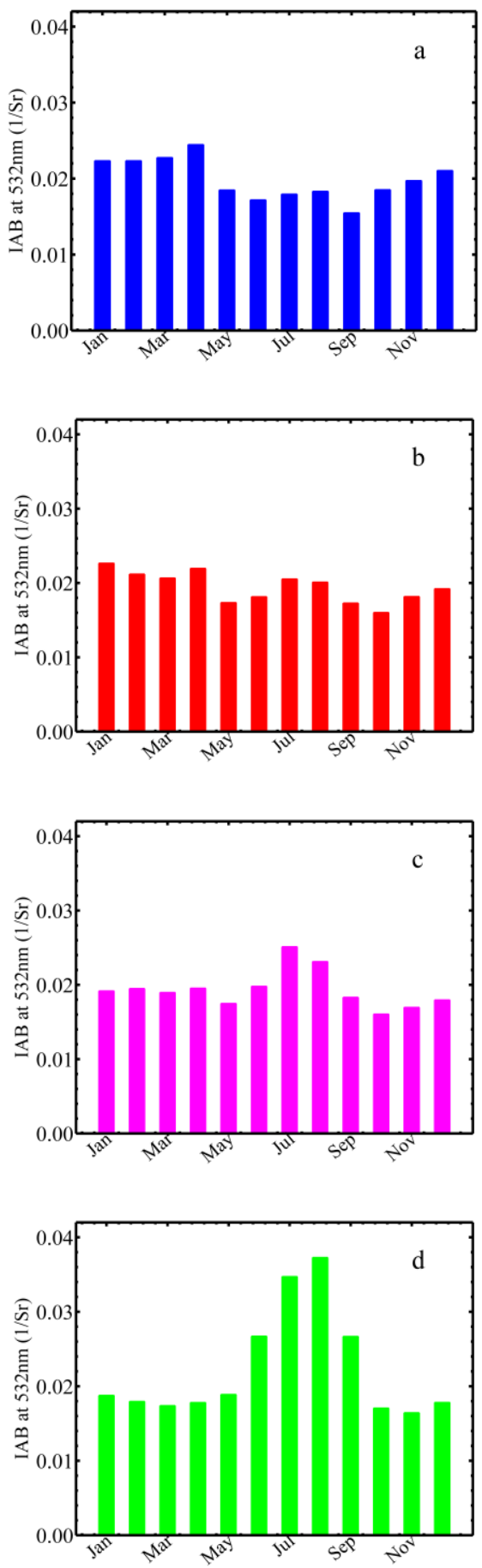

Figure 2. Monthly averaged IAB over four regions (a to d, region 1 to 4), CALIPSO level 2 / aerosol profile V3, Jun. 2006 to Dec. 2015. 
Four-month averaged $700 \mathrm{hPa}$ wind field over the region are shown in Figures $4 \mathrm{a}-4 \mathrm{c}$. The wind patterns are calculated using NCEP/NCAR reanalysis for years 2006-2015. Similar behavior also can be observed when one looks to the variations of PDR versus IAB (not shown here).
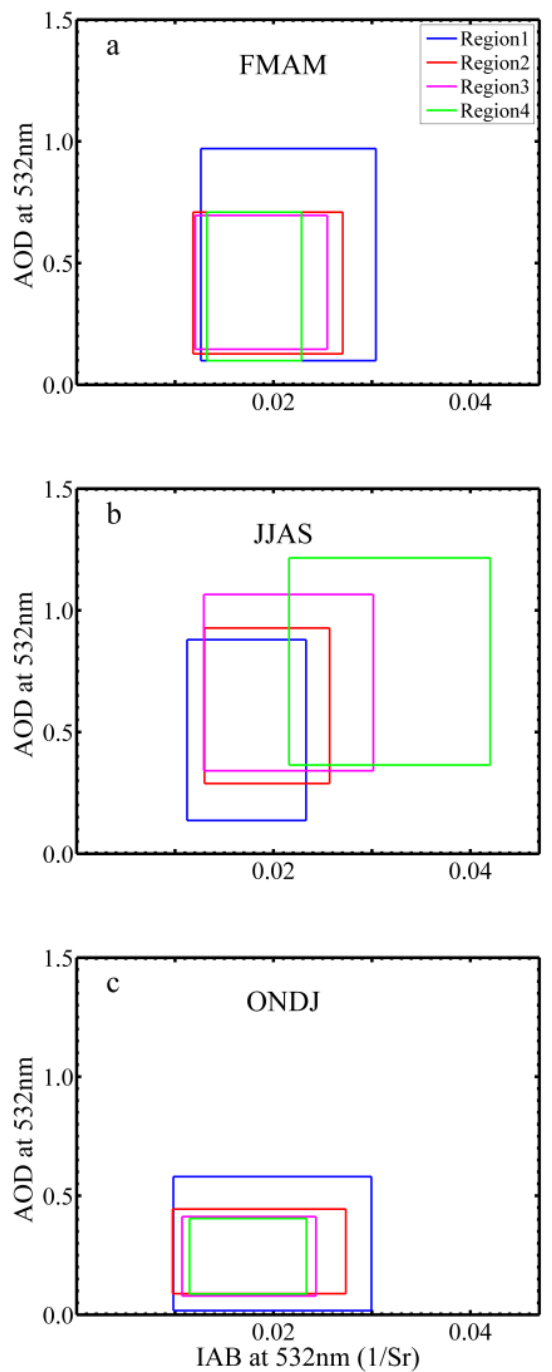

Figure 3. 4-month averaged AOD Vs. IAB, a- February to May, $b$ - June to September, c-October to January, CALIPSO level 2 / aerosol profile V3, Jun. 2006 to Dec. 2015.

\section{CONCLUSIONS}

The obtained results which parts of them are shown in Figure 2 and Figure 3 indicate that the atmosphere over the Persian Gulf, Oman and Arab seas experiences frequent dust outbreaks especially during spring and summer times. As we divided the whole area into four sub regions (Figure 1), it has been found that in region 1, the occurrence rate of dust storms has its maximum value in May. But for
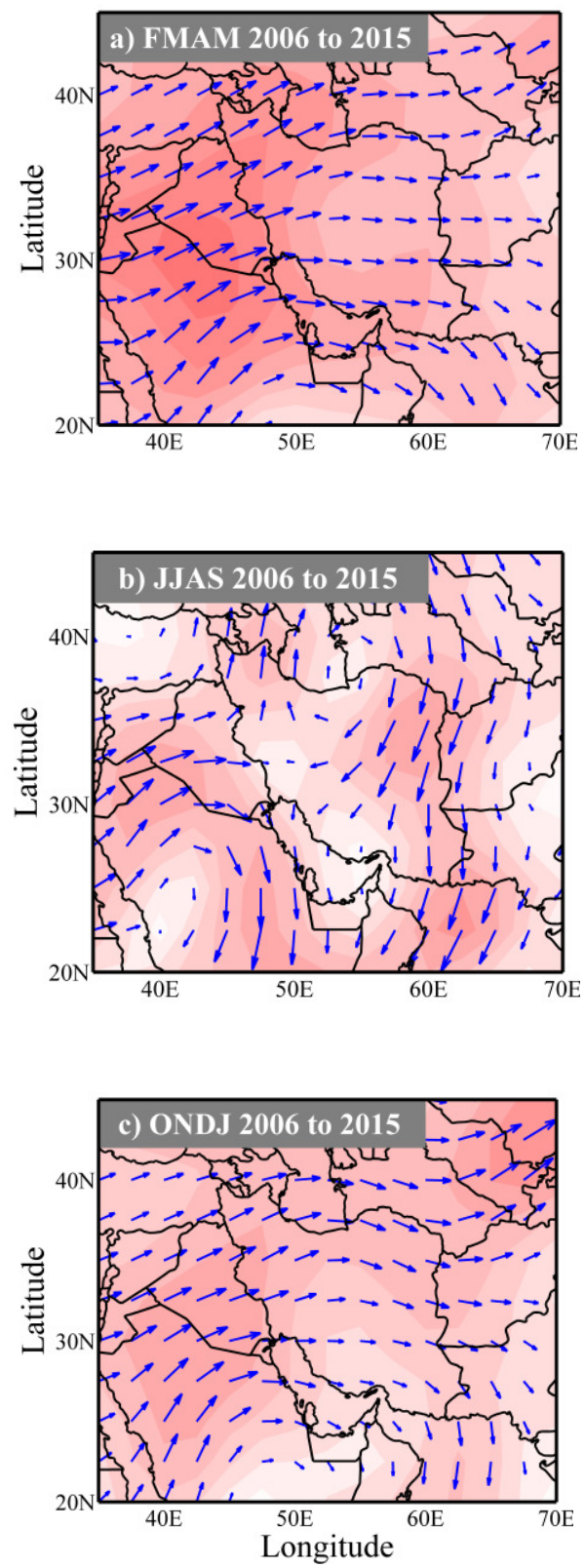

$\mathrm{V}(\mathrm{m} / \mathrm{s})$

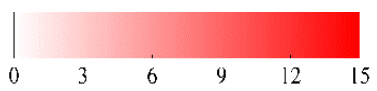

Figure 4. 4-month averaged wind field over the Iran plateau during 2006 to 2015 at $700 \mathrm{hPa}$, a- February to May, b-June to September, c-October to January, NCEP/NCAR reanalysis.

the other three regions, this is happening in July. Looking to the wind pattern over the region [12] one can find that region 1 is quite affected by dust 
storms originated from the Tigris and Euphrates basin but regions 2 and 3 are mostly under influence of dust plums advected from the Arabian Peninsula. The interesting case is with region 4. Looking to Figure $3 \mathrm{c}$ one can clearly find that during June to September, dust storms are very frequent and intense in this region. This is in exact temporal coincidence with the annual cycle of 120 day Sistan Levar wind (Figure 4b).

In other words, this northerly wind takes the dust from the bed of seasonal Hamoun lake and transport it to Southeast Iran, West Pakistan, Oman and Arab seas and sometimes it even may affect the Indian ocean. It is interesting to see that CALIPSO recordings especially on IAB can distinguish between the dust that advected from the Arabian Peninsula and those from the Hamoun lake. Therefore, IAB can be introduced as a powerful tool on characterization of atmospheric particles, especially when its variations respect to AOD and PDR have been considered.

\section{ACKNOWLEDGEMENTS}

Authors are grateful to NASA Langley Research Center for providing the CALIPSO data (http://eosweb.larc.nasa.gov/). The NCEP/NCAR reanalysis data is prepared through the NOAA Climate Diagnostics Center/National Oceanic and Atmospheric Administration, at Boulder, Colorado (http://www.esrl.noaa.gov/). They also thank Ruhollah Moradhaseli for valuable discussions.

\section{References}

[1] Prospero, J. M., Ginoux, P., Torres, O., Nicholson, S. E. and Gill, T. E., 2002: Environmental characterization of global sources of atmospheric soil dust identified with the Nimbus 7 Total Ozone Mapping Spectrometer (TOMS) absorbing aerosol product, Rev. Geophys, 40 (1), 1002pp.

[2] Abdi Vishkaee, F., Flamant, C., Cuesta, J., Flamant, P. and Khalesifard, H.R., 2011: Multiplatform observations of dust vertical distribution during transport over northwest Iran in the summertime, Journal of Geophysical Research: Atmospheres, 116 (D5).
[3] Ginoux, P., Prospero, J. M., Gill, T. E., Hsu, N. C. and Zhao, M., 2012: Global-scale attribution of anthropogenic and natural dust sources and their emission rates based on MODIS Deep Blue aerosol products, Reviews of Geophysics, 50 (3).

[4] Goudie, A. and Middleton, N. J., 2006: Desert dust in the global system, Springer Science \& Business Media.

[5] Badarinath, K. V. S., Kharol, S.K., Kaskaoutis, D. G., Sharma, A. R., Ramaswamy, V. and Kambezidis, H. D., 2010: Long-range transport of dust aerosols over the Arabian Sea and Indian region - A case study using satellite data and ground-based measurements, Global and Planetary Change, 72 (3), 164-181.

[6] Kaskaoutis, D. G., Gautam, R., Singh, R. P., Houssos, E. E., Goto, D., Singh, S., Bartzokas, A., Kosmopoulos, P. G., Sharma, M., Hsu, N. C. and Holben, B. N., 2012: Influence of anomalous dry conditions on aerosols over India: transport, distribution and properties, Journal of Geophysical Research: Atmospheres, 117 (D9).

[7] Abdi Vishkaee, F., Flamant, C., Cuesta, J., Oolman, L., Flamant, P. and Khalesifard, H.R., 2012: Dust transport over Iraq and northwest Iran associated with winter Shamal: A case study, Journal of Geophysical Research: Atmospheres, 117 (D3).

[8] Rashki, A., Kaskaoutis, D. G., Eriksson, P. G., Qiang, M. and Gupta, P., 2012: Dust storms and their horizontal dust loading in the Sistan region, Iran. Aeolian Research, 5, 51-62.

[9] Rashki, A., Kaskaoutis, D. G., Goudie, A. S. and Kahn, R. A., 2013: Dryness of ephemeral lakes and consequences for dust activity: the case of the Hamoun drainage basin, southeastern Iran, Science of the Total Environment, 463, 552-564.

[10] Middleton, N. J., 1986: A geography of dust storms in South-west Asia, Journal of Climatology, 6 (2), 183-196.

[11] McMahon, H., 1906: Recent survey and exploration in Seistan. The Geographical Journal, 28 (3), 209-228.

[12] Alizadeh-Choobari, O., Zawar-Reza, P. and Sturman, A., 2014: The "wind of 120days" and dust storm activity over the Sistan Basin. Atmospheric Research, 143, 328-341. 